\title{
COMPORTAMENTO DA CULTIVAR NIÁGARA ROSADA ENXERTADA SOBRE DIFERENTES PORTA-ENXERTOS NO SUL DE SANTA CATARINA, BRASIL ${ }^{1}$
}

\author{
EMÍLIO DELLA BRUNA² \& ÁLVARO JOSÉ BACK ${ }^{3}$
}

RESUMO-A videira 'Niagara Rosada' é a principal cultivar de uva de mesa plantada no Sul do Brasil. Para avaliar a qualidade da uva produzida, foi conduzido um experimento com a Niagara Rosada nos seguintes porta-enxertos: 'Jales', 'Tropical', 'Campinas', 'VR 043-43', 'R-99', 'Paulsen 1103', 'Schwarzmann', 'Traviú', 'Golias', 'Gravesac', 'RR 101-14', 'Dog Ridge', 'VR 044-4', 'Kobber 5BB' e 'SO4', mais o pé-franco. Foram avaliados a fenologia, o vigor, a sobrevivência das plantas e a produção (produtividade, tamanho do cacho e número de cachos por planta). Os diferentes porta-enxertos não influenciam na fenologia da planta. O maior vigor foi observado para o 'Dog Ridge', seguido do 'Campinas', 'Paulsen 1103' e 'VR 043-43'. As maiores mortalidades de planta ocorreram para pé-franco (56\%), 'Traviú' (50\%) e 'Schwarzmann' (41\%). Os porta-enxertos 'Paulsen 1103', 'Campinas' e 'Golias', além de alta produtividade, apresentam cachos maiores e mais compactos.

Termos para indexação: Viticultura; produção de uva; uva de mesa; Vitis.

\section{BEHAVIOR OF NIAGARA ROSADA CULTIVAR GRAFTED ON DIFFERENT ROOTSTOCKS IN THE SOUTH OF SANTA CATARINA, BRAZIL}

\begin{abstract}
The 'Niagara Rosada' vine is the main variety of table grape grown in southern Brazil. To improve the quality of grapes produced, an experiment was conducted with the following rootstocks: 'Jales', 'Tropical', 'Campinas', 'VR 043-43', 'R-99', 'Paulsen 1103', 'Schwarzmann', 'Traviú', 'Golias', 'Gravesac', 'RR 101-14', 'Dog Ridge', 'VR 044-4', 'Kobber 5BB' and 'SO4', and the ungrafted. The phenology, the vigour, the survival rate and the production of the plants (productivity, bunch size and number of bunches per plant) were evaluated. The different rootstocks do not influence the plant phenology. The greatest vigour was found in the 'Dog Ridge' rootstock, followed by the 'Campinas', the 'Paulsen 1103' and the 'VR 04343 '. The highest mortality rates of the plants, after 11 years of experiment happened to the ungrafted $(56 \%)$, Traviu' (50\%) and 'Schwarzmann' (41\%). The 'Paulsen 1103', 'Campinas' and 'Golias' rootstocks, besides a high productivity, presented the largest size and the best presentation of bunches.
\end{abstract}

Index terms: Viticulture; grape production; table grape, Vitis.

${ }^{1}$ (Trabalho 245-14). Recebido em: 03-09-2014. Aceito para publicação em: 20-05-2015.

${ }^{2}$ Eng $^{\mathrm{o}}$ Agr $^{\mathrm{o}}$., Me., Pesquisador Epagri - Estação Experimental de Urussanga. E-mail: emilio@epagri.sc.gov.br

${ }^{3}$ Eng $^{\circ}$ Agr $^{\circ}$., Dr. Pesquisador Epagri - Estação Experimental de Urussanga. E-mail: ajb@epagri.sc.gov.br 


\section{INTRODUÇÃO}

A videira 'Niágara Rosada' destaca-se como uma das uvas de mesa preferidas pelo consumidor brasileiro, sendo a principal cultivar plantada nos Estados de Santa Catarina, São Paulo e Minas Gerais (FERREIRA et al., 2004). A enxertia de videira como meio de propagação é conhecida desde o século II A.C ; entretanto, este método de propagação só foi amplamente usado em videira após 1800 para combater a filoxera, Phylloxera vitifoliae (Fitch), um afídeo que danifica as raízes da videira (FERRIS et al.. 2012). Os viticultores tiveram de fazer uso de porta-enxertos tolerantes ou resistentes a esta praga. As plantas usadas como porta-enxerto eram nativas da América do Norte, onde a praga ocorre naturalmente. De acordo com Camargo (2003), no Brasil,, o uso de porta-enxertos iniciou a partir de 1920 com o início do cultivo de uvas europeias (Vitis viníferas).

As condições fundamentais exigidas para um bom porta-enxerto em viticultura incluem resistência a filoxera e nematoides, adaptação ao ambiente, facilidade de propagação, afinidade satisfatória com as cultivares-copa, e sanidade (HIDALGO, 1993). Apesar da disponibilidade razoável de bons portaenxertos, cada um deles tem sua limitação, e só a experimentação regional poderá determinar qual é o mais adequado para cada condição de cultivo (POMMER et al., 1997). A relação copa/porta-enxerto em viticultura é avaliada por diversas interações e respostas no potencial vegetativo e produtivo das plantas, bem como na qualidade dos frutos (PASTENA, 1981). Em geral, videiras enxertadas apresentam maior vigor e maior produtividade do que videiras de pé-franco (EDWARDS, 1988). Na busca da combinação ideal entre porta-enxerto e variedades-copa, inúmeros trabalhos têm sido realizados e deverão continuar sendo realizados, uma vez que são inúmeras as variáveis que atuam sobre essa combinação, fazendo com que, para cada uma delas, possa haver um par ideal (ALVARENGA et al., 2002). Em estudo desenvolvido na região de Jundiaí-SP, com o cultivar Niagara Rosada, as melhores produções foram obtidas quando se utilizou o porta-enxerto 'Schwarzmann', que não diferiu dos porta-enxertos 'Golia', 'Traviú', 'Jales' e 'IAC 571-6'. No entanto, os porta-enxertos não influenciaram no peso médio dos cachos (TERRA et al., 2003). Na região do Vale do Paraíba-SP, Pauletto (2001a), comparando diferentes porta-enxertos para o cultivar Niagara Rosada, verificou maiores produções quando as plantas foram enxertadas sobre 'Campinas', 'Tropical' e 'Traviú', superando os porta-enxertos 'Kober 5BB' e 'Schwarzmann'. Em outro experimento conduzido na região de Mococa-SP, por cinco anos consecutivos, as melhores produções para a uva 'Niagara Rosada' foram observadas quando se utilizaram os porta-enxertos 'Jales' e 'Tropical', e maior desenvolvimento vegetativo com os porta-enxertos 'Campinas' e 'Tropical' (TERRA et al., 2003). Para o cultivar Concord, também na região de Mococa-SP, Terra et al. (2001) verificaram maiores produções quando as plantas foram enxertadas sobre 'Tropical', 'IAC 571-6' e 'Jales'. O pior desempenho foi constatado quando se utilizou o porta-enxerto 'Campinas'. No município de Caldas-MG, Alvarenga et al. (2002) observaram que o porta-enxerto 'Campinas' induziu a produção do maior número de cachos para o cultivar Niagara Rosada. Para a variável produção total, estes autores verificaram superioridade quando as plantas foram enxertadas sobre os porta-enxertos 'Campinas' e 'Jales'. O presente trabalho teve como objetivo avaliar o desempenho de diferentes portaenxertos sobre os componentes de produção e o comportamento fenológico da 'Niagara Rosada' no litoral sul de Santa Catarina.

\section{MATERIAL E MÉTODOS}

O presente trabalho foi instalado na Epagri, Estação Experimental de Urussanga (coordenadas $28^{\circ} 32^{\prime} 01^{\prime \prime} \mathrm{S}$ e $49^{\circ} 18^{\prime} 50^{\prime}$ ' W, com altitude de 52 metros), cujo clima apresenta temperatura média anual de $19^{\circ} \mathrm{C}$, com média das mínimas de $13^{\circ} \mathrm{C}$ e das máximas de $26^{\circ} \mathrm{C}$, umidade relativa de $75 \%$ e precipitação pluviométrica anual média de 1.600 mm . O solo da área experimental é classificado com Argissolo Vermelho-Amarelo.

No experimento, foi utilizado o delineamento em blocos ao acaso, com 16 tratamentos, representados por 15 porta-enxertos, a saber: IAC 766 'Campinas'; IAC 313 'Tropical'; IAC 572 'Jales'; 'VR 043-43’; 'R-99'; 'Paulsen 1103'; 'Schwarzmann'; 'Traviú'; 'Golias'; 'Gravesac', '101-14'; 'Dog Ridge', VR 044-4';'Kobber 5BB', e 'SO4', mais o péfranco da variedade produtora. Foram utilizadas cinco repetições e avaliadas cinco plantas por parcela, perfazendo 400 plantas. Os tratamentos fitossanitários foram feitos com pulverizações semanais com fungicidas recomendados para a cultura, e as adubações conforme recomendação da Sociedade Brasileira de Ciência do Solo (2004). As mudas enxertadas foram plantadas a campo, em agosto de 1992, no espaçamento de 1,5 metro entre plantas e 3 metros entre linhas, e conduzidas no sistema de latada. 
Nos anos de 1996, 1997, 1998, 1999, 2002, 2003 e 2004, foi avaliada a fenologia: data do início da brotação ( $50 \%$ das gemas com ponta verde); data do início da floração (5\% das flores abertas); data da plena floração ( $50 \%$ das flores abertas); data do final da floração (mais de 95 das flores abertas); data da colheita e a exigência térmica (somatório de graus dias (GD), desde o início da brotação até a colheita), conforme metodologia proposta por Villa Nova et al. (1972). Também foram avaliados a produtividade ( $\mathrm{kg}$ de frutos $\mathrm{ha}^{-1}$ ), o vigor das plantas ( $\mathrm{kg}$ de bacelos retirados durante a poda de inverno) e a mortalidade de plantas. Nos anos de 2000 e 2001, os dados não foram considerados devido a um forte ataque de Míldio (Plasmopara viticola) no ano de 2000, causado pela aplicação inadequada de fungicida, o que provocou a queda dos frutos e a queda precoce das folhas, prejudicando assim as duas safras não avaliadas.

Os dados foram analisados com o programa SPSS (Statistical Package for Social Sciences). A avaliação dos componentes de produção e a fenologia foram baseadas na análise de variância, e a comparação das médias foi realizada com o teste de Duncan, adotando nível de significância de 5\%.

\section{RESULTADO E DISCUSSÃO}

As plantas em 'Pé-franco' apresentaram menor vigor, menor produtividade, menor número de cachos e menor peso médio do cacho quando comparadas com as plantas enxertadas (Tabela 1). Resultados semelhantes foram registrados por Alvarenga et al. (2002), quando estudaram o comportamento de diferentes porta-enxertos sobre a produção da cultivar Niágara Rosada em solos ácidos, no município de Caldas, sul do Estado de Minas Gerais. Os mesmos autores afirmam que plantas de videira que crescem sobre suas próprias raízes têm a tendência de ser menos vigorosas, produzindo menos frutos e apresentar cachos menores. O efeito negativo que as plantas em péfranco apresentam no crescimento vegetativo e na produção, pode ser minimizado quando plantadas em solo de alta fertilidade, bem drenados e isentos de pragas. Inúmeros trabalhos têm demonstrado o efeito benéfico do uso de porta-enxerto sobre o vigor (ALVARENGA et al., 2002), sobre a resistência a doenças (BILLONES-BAAIJENS et al., 2014; MUROLO; ROMANAZZI, 2014), sobre à resistência seca (SERRA et al., 2014; TSEGAY et al., 2014), sobre a tolerância a solos encharcados e salinos (JOGAIAH et al., 2014), sobre a produção (PAULETTO et al., 2001a; PAULETTO et al., 2001b;
SILVA et al., 2010), e sobre a fisiologia da planta (SATO et al., 2009; COOKSON; OLLAT, 2013).

As plantas de pé-franco, a partir do $6^{\circ}$ ano de vida, começaram a apresentar mortalidade, chegando ao $11^{\circ}$ ano com apenas $44 \%$ das plantas sobreviventes (Tabela 2). Dentre as plantas enxertadas, a morte precoce de plantas foi variável e progressiva com a idade, para os diferentes porta-enxertos. As plantas enxertadas sobre 'Schwarzmann' começaram a morrer logo no quarto ano de vida, fenômeno que ocorre em pomares comerciais da região quando plantados sobre este porta-enxerto. A mortandade observada ao final do $11^{\circ}$ ano foi de $50 \%$ para 'Traviu', 41\% para 'Schwarzmann', 27\% para 'VR 044-4' e $24 \%$ para ' $101-14$ '. As mortes ocorreram devido ao definhamento progressivo das plantas, começando com a perda de vigor, secamento de ramos até à morte completa da planta. As plantas mortas foram analisadas e não apresentaram ataque de cochonilhas de raiz, cochonilha do tronco nem infecção por Fusarium, que são as três principais causas de morte dos vinhedos no Sul do Brasil. Garrido et al. (2004), estudando o declínio e a morte de videiras no Rio Grande do Sul, encontraram vários fungos associados à morte de plantas, sendo as principais espécies: Cylindrocarpon sp.; Phaeoacremonium sp.; Verticillium sp.; Botryosphaeria sp.; Fusarium oxysporum f.sp. herbemontis; Graphium sp., e Cylindrocladium sp. Também observaram que a maior incidência de fungos ocorreu em plantas propagadas por estaquia em pé-franco $(50,4 \%)$, quando comparadas com as plantas enxertadas $(11,2 \%)$. Para as plantas enxertadas sobre os portaenxertos 'Campinas', 'Tropical', 'Dog Ridge' e 'SO4', a mortandade após o $11^{\circ}$ ano foi inferir a $10 \%$.

Os diferentes porta-enxertos não influenciaram sobre as variáveis fenológicas da videira. As épocas de brotação, de floração e de maturação dos frutos não apresentaram diferenças entre os 15 portaenxertos testados e também para o pé-franco. Também, o tempo, contado em dias, necessário para a planta completar cada etapa do ciclo, da brotação ao início da floração, da brotação à plena floração, da brotação ao final da floração e da brotação até a colheita, não apresentou diferença para os diferentes porta-enxertos testados (Tabela 3). Também a necessidade de calor, expressa em graus- dia, necessária para a videira completar o ciclo, do início da brotação à colheita, que foi em média de 1.430 graus-dia, não apresentou diferenças significativas para os diferentes porta-enxertos estudados (Tabela 3). Estes dados estão de acordo com Back e Bruna (2012) que, estudando a fenologia e o requerimento 
térmico para esta cultivar, determinaram que a duração média do ciclo, da brotação à colheita, é de aproximadamente 124 dias, e que a necessidade térmica é de 1.442 graus-dia, considerando a temperatura base de $10^{\circ}$ Célsius. Alvarenga et al. (2002), avaliando as cultivares Niágara Rosada, e Gonçalves et al. (2002), avaliando a cultivar Folha de Figo, também não encontraram influência dos porta-enxertos sobre o ciclo destas cultivares, considerando o período do início da brotação até à colheita. As datas de brotação foram diferentes para os diversos anos do experimento:15-8-1996, 8-91997, 27-8-1998, 22-8-1999, 22-8-2001, 16-9-2002, 19-9-2003 e 8-9-2004, respectivamente. A variação nas datas de brotação deveu-se às temperaturas ocorridas nos meses de maio, junho, julho e agosto (Figura 2). Árvores frutíferas em regiões temperadas entram em dormência no outono e inverno, como estratégia adaptativa para se proteger das condições desfavoráveis para o crescimento (LUEDELING et al., 2013; JONES et al., 2013). A necessidade de frio e de calor são os principais fatores determinantes na quebra de dormência das plantas (LUEDELING et al., 2013; CAMPOY et al., 2011). Nos meses de maio, junho, julho e na primeira semana de agosto, ocorreu o acúmulo de unidades de frio e, a partir da segunda semana de agosto, quando as plantas foram podadas, o acúmulo de calor foi responsável pela brotação. O acúmulo de calor, medido em graus-dia, ocorrido entre a poda e o início da brotação, foi de $160 ; 205 ; 175 ; 168 ; 198 ; 169 ; 178$ e 180 para os anos de 1996, 1997, 1998, 1999, 2001, 2002, 2003 e 2004. Nos anos em que ocorreu pequeno acúmulo de frio hibernal, como em 1997, a planta precisou maior acúmulo de calor para iniciar a brotação, retardando assim o início da brotação, quando comparado com 1999, onde o acúmulo de frio hibernal foi maior. Já nos anos de 2002, 2003 e 2004, a brotação também foi retardada. Nesses anos, embora tenha ocorrido boa acumulação de frio hibernal nos meses de maio, junho e julho, as temperaturas permaneceram baixas após a poda (Figura 2), e as plantas necessitaram de maior período para acumular os graus-dias necessários para desencadear o início da brotação.

$\mathrm{O}$ vigor das plantas, medido pelo peso dos bacelos retirados durante a poda de inverno, foi significativamente influenciado pelos porta-enxertos (Tabela 1). O 'Dog Ridge' apresentou o maior vigor, com a média de 742,1 gramas de ramos podados por ano, quase o dobro da segunda cultivar mais vigorosa, a 'Campinas', com 469,1 gramas de ramos podados. Menor vigor foi observado para o pé-franco, ' Gravesac', 'Schwarzmann', 'Kobber 5BB', 'SO4' e “101-14”, cujos pesos médios dos ramos podados variaram de 99,2 g para plantas de pé-franco até 208,3 g para o porta-enxerto "101-14". A avaliação do vigor que o porta-enxerto proporciona à copa é de fundamental importância para a escolha da combinação ideal entre o porta-enxerto e a copa, e das técnicas de produção a serem adotadas. Para os porta-enxertos mais vigorosos, recomendam-se o plantio em espaçamentos mais largos, solos de menor fertilidade e redução da adubação nitrogenada. $\mathrm{O}$ vigor adequado, sem que o excesso ou a falta desse venha a se traduzir em redução da produtividade, deve ser buscado adotando-se técnicas de produção adequadas para cada combinação, como desponte, poda verde e poda seca diferenciada com aumento do número de gema para plantas mais vigorosas (ALVARENGA et al., 2002).

A produção média de frutos nos sete anos avaliados foi maior de 35,7 ton.ha ${ }^{-1}$ para os portaenxertos 'Paulsen 1103', 'Dog Ridge', 'Campinas'e 'Tropical', cujas médias não diferiram entre o nível de significância de $5 \%$. Para os porta-enxertos 'Golias', 'Jales', 'VR 043-43', '101-14' e 'Traviú', a produção foi superior a $32 \mathrm{t}$. ha $\mathrm{ha}^{-1}$, diferindo significativamente do grupo anterior somente para o porta-enxerto 'Paulsen 1103". A produção destes nove porta- enxertos foi significativamente superior ao 'R99', 'Kobber 5BB', 'Gravesac', 'Schwarzmann', 'VR 044-4' e pé-franco (Tabela 1). Estes dados estão de acordo com Pauletto (2001a), que verificou para a 'Niágara Rosada' maiores produções quando as plantas foram enxertadas sobre 'Campinas', 'Tropical' e 'Traviú', superando os porta-enxertos 'Kobber 5BB' e 'Schwarzmann'. $\mathrm{O}$ 'Dog Ridge', mesmo com a alta produtividade $\left(37,09\right.$ t. ha $\left.\mathrm{h}^{-1}\right)$, não deve ser recomendado para plantio, quando o objetivo da produção é o mercado in natura por produzir cachos malformados com bagas muito espaçadas e sem valor comercial. A arquitetura do cacho pode ser melhorada com o aumento do espaçamento desta cultivar, visto que o vigor foi excessivamente alto (Tabela1) para o espaçamento usado. Os porta-enxertos 'Tropical' e 'Jales' apresentaram ótima produtividade (em torno de 35 t. ha. ${ }^{-1}$ ) e cachos compactos com bom tamanho (em torno de 254 gramas), entretanto apresentaram baga com coloração esverdeada que deprecia seu valor de mercado. Portanto, afirma-se que a coloração deficiente pode ter sido ocasionada pela combinação porta-enxerto e altas temperaturas noturnas no período de maturação, além do excesso de chuva que ocorre nesta época do ano.

Na Análise de Variância, foi observado que existem diferenças significativas na produtividade entre os anos $(p<0,0001)$ e também entre os porta- 
enxertos $(p<0,0001)$, e ainda que a interação entre ano e porta-enxerto foi significativa ( $\mathrm{p}<0,0001)$. Esta interação significativa pode ser explicada pelo comportamento diferenciado dos porta-enxertos 'Campinas' e 'Dog Ridge', que, no ano de 2004, apresentaram aumento de produção, enquanto os demais apresentaram diminuição da produtividade (Figura 1B ). Também pode-se destacar que, no ano de 1998, o porta-enxerto 'Dog Ridge' apresentou diminuição da produtividade, enquanto os demais apresentaram aumento.

A variação na produtividade da 'Niágara Rosada' é comum na região, mas as causas dessa variação ainda não foram entendidas; entretanto, sempre após um ano de alta produtividade, no ano seguinte, a produção diminui (Figura 1B). O número de cachos produzidos por planta e sua massa foram diferentes para os diversos porta-enxertos, variando em número e tamanho de forma proporcional para cada ano de avaliação (Figura1A e Figura 1C). A produtividade é uma relação direta do número de cacho produzido por planta e do peso desses cachos; portanto, os porta-enxertos que apresentaram maior número de cacho e com peso maior apresentaram as maiores produtividades (Tabela1). Para a 'Niágara Rosada' destinada ao consumo in natura, o tamanho do cacho, bem como sua arquitetura de forma compacta, define seu valor comercial. $\mathrm{O}$ 'Paulsen 1103', 'Campinas', 'Golias' e' VR 04343' apresentaram o melhor conjunto, produtividade, tamanho de cacho, arquitetura do cacho e coloração das bagas, sendo, portanto, superiores aos demais porta-enxertos estudados.

TABELA 1-Número de cachos por planta, peso dos cachos, produção de frutos em t/ha e peso dos bacelos podados no inverno da videira 'Niágara Rosada' enxertada sobre diferentes porta-enxerto e em pé-franco. Média das safras 1996, 1997, 1998, 2002, 2003 e 2004`.

\begin{tabular}{|c|c|c|c|c|}
\hline \multirow[b]{2}{*}{ Porta-enxerto } & \multicolumn{2}{|c|}{ Cacho } & \multirow{2}{*}{$\begin{array}{l}\text { Produção } \\
\text { (t/ha) }\end{array}$} & \multirow{2}{*}{$\begin{array}{l}\text { Peso dos bacelos } \\
\text { (gramas/planta) }\end{array}$} \\
\hline & $\mathrm{N}^{\mathrm{o} / \text { planta }}$ & Peso (g) & & \\
\hline Paulsen 1103 & $75,4 \mathrm{a}$ & $247,3 \mathrm{abc}$ & $39,66 \mathrm{a}$ & 432,9 bc \\
\hline Dog Ridge & 66,0 bc & $264,9 \mathrm{ab}$ & $37,09 \mathrm{ab}$ & $742,1 \mathrm{a}$ \\
\hline Campinas & 61,3 bcd & $267,5 \mathrm{ab}$ & $36,37 \mathrm{ab}$ & $469,1 \mathrm{~b}$ \\
\hline Tropical & 64,5 bc & $254,2 \mathrm{ab}$ & $35,77 \mathrm{ab}$ & $339,3 \mathrm{~cd}$ \\
\hline Golias & 62,1 bcd & $270,7 \mathrm{a}$ & $35,14 \quad b$ & 263,7 de \\
\hline Jales & 64,9 bc & $253,7 \mathrm{ab}$ & $34,97 \quad b$ & 221,6 ef \\
\hline VR 043-43 & 61,0 bcde & 238,8 bcd & $34,79 \quad b$ & 374,1 bcd \\
\hline $101-14$ & $69,6 \mathrm{ab}$ & 222,3 bcd & 33,60 bc & $208,3 \quad$ efg \\
\hline Traviú & $69,5 \mathrm{ab}$ & 218,6 bcd & 32,94 bc & $353,1 \mathrm{~cd}$ \\
\hline $\mathrm{SO} 4$ & 66,6 bc & 210,3 def & $30,69 \mathrm{~cd}$ & 204,5 efg \\
\hline R-99 & $60,0 \quad$ cdef & 219,2 bcd & 28,77 & 224,1 \\
\hline Kobber 5BB & $54 \quad$ defg & 222,5 bcd & 25,37 & 207,5 \\
\hline Gravesac & efg & 204,7 & 23,49 & $142,1 \quad \mathrm{fg}$ \\
\hline Schwarzmann & 52 & 188,9 & 21,89 & $202,7 \quad$ efg \\
\hline VR 044-4 & 47 & 219,0 bcd & 21,56 & 305,8 de \\
\hline Pé-franco & 30 & 136,4 & 10,23 & $99,2 \quad \mathrm{~g}$ \\
\hline
\end{tabular}

${ }^{1}$ Médias seguidas pela mesma letra não diferem entre si, pelo teste de Duncan, ao nível de significância de 5 \%. 
TABELA 2- Sobrevivência de plantas (\%) de videira 'Niágara Rosada' enxertadas sobre diferentes portaenxertos e em pé-franco, em função da idade da planta.

\begin{tabular}{lrrrrrrr}
\hline \multicolumn{1}{c}{$\begin{array}{c}\text { Nome do } \\
\text { porta-enxerto }\end{array}$} & \multicolumn{7}{c}{$\%$ de plantas sobreviventes em função da idade } \\
\cline { 2 - 8 } & $3^{\circ}$ ano & $4^{\circ}$ ano & $5^{\circ}$ ano & $6^{\circ}$ ano & $9^{\circ}$ ano & $10^{\circ}$ ano & $11^{\circ}$ ano \\
\hline Tropical & 100 & 100 & 100 & 100 & 100 & 100 & 96 \\
Dog Ridge & 100 & 100 & 100 & 100 & 93 & 93 & 93 \\
SO4 & 100 & 100 & 100 & 100 & 100 & 97 & 93 \\
Campinas & 100 & 100 & 100 & 100 & 100 & 96 & 93 \\
043-43 & 100 & 100 & 100 & 100 & 88 & 88 & 88 \\
Golias & 100 & 100 & 97 & 97 & 93 & 90 & 87 \\
Jales & 100 & 100 & 100 & 100 & 96 & 96 & 86 \\
R-99 & 100 & 100 & 100 & 96 & 96 & 96 & 85 \\
Kobber 5BB & 100 & 96 & 93 & 93 & 89 & 81 & 81 \\
Paulsen 1103 & 100 & 100 & 100 & 95 & 95 & 85 & 80 \\
Gravesac & 100 & 100 & 100 & 100 & 92 & 92 & 80 \\
101-14 & 100 & 100 & 97 & 93 & 76 & 76 & 76 \\
044-4 & 100 & 91 & 91 & 91 & 82 & 82 & 73 \\
Schwarzmann & 100 & 89 & 81 & 78 & 70 & 59 & 59 \\
Traviúy & 100 & 100 & 100 & 96 & 77 & 65 & 50 \\
Pé-Franco & 100 & 100 & 100 & 93 & 63 & 48 & 44 \\
\hline
\end{tabular}

TABELA3-Ciclo em dias e exigência térmica, expressa em graus-dia, da videira 'Niágara Rosada' enxertada sobre diferentes porta-enxertos e em pé-franco. Média de sete ciclos.

\begin{tabular}{|c|c|c|c|c|c|}
\hline \multirow{2}{*}{ Porta-enxerto } & \multicolumn{4}{|c|}{ Ciclo em dias a partir da brotação } & \multirow{2}{*}{$\begin{array}{c}\text { Graus-Dia } \\
\text { brotação } \\
\text { a } \\
\text { colheita }\end{array}$} \\
\hline & IF & $\mathrm{PF}$ & $\mathrm{FF}$ & $\mathrm{C}$ & \\
\hline Campinas & 24 & 27 & 30 & 120 & 1420 \\
\hline Jales & 25 & 28 & 31 & 122 & 1450 \\
\hline Tropical & 24 & 27 & 30 & 120 & 1425 \\
\hline VR 043-43 & 24 & 27 & 30 & 120 & 1420 \\
\hline R-99 & 24 & 27 & 30 & 121 & 1432 \\
\hline Paulsen 1103 & 25 & 28 & 30 & 121 & 1435 \\
\hline Schwarzmann & 24 & 28 & 31 & 120 & 1425 \\
\hline $101-14$ & 24 & 27 & 30 & 120 & 1422 \\
\hline Gravesac & 25 & 28 & 31 & 121 & 1435 \\
\hline Golias & 24 & 27 & 30 & 121 & 1430 \\
\hline Traviú & 25 & 28 & 31 & 120 & 1425 \\
\hline Dog Ridge & 25 & 29 & 31 & 121 & 1438 \\
\hline VR 044-4 & 25 & 27 & 30 & 121 & 1436 \\
\hline Pé-franco & 25 & 28 & 30 & 122 & 1442 \\
\hline Kobber 5BB & 24 & 27 & 30 & 120 & 1420 \\
\hline $\mathrm{SO} 4$ & 24 & 28 & 31 & 121 & 1435 \\
\hline $\mathrm{p}$ & 0,999 & 0,999 & 0,999 & 0,999 & 0,998 \\
\hline
\end{tabular}



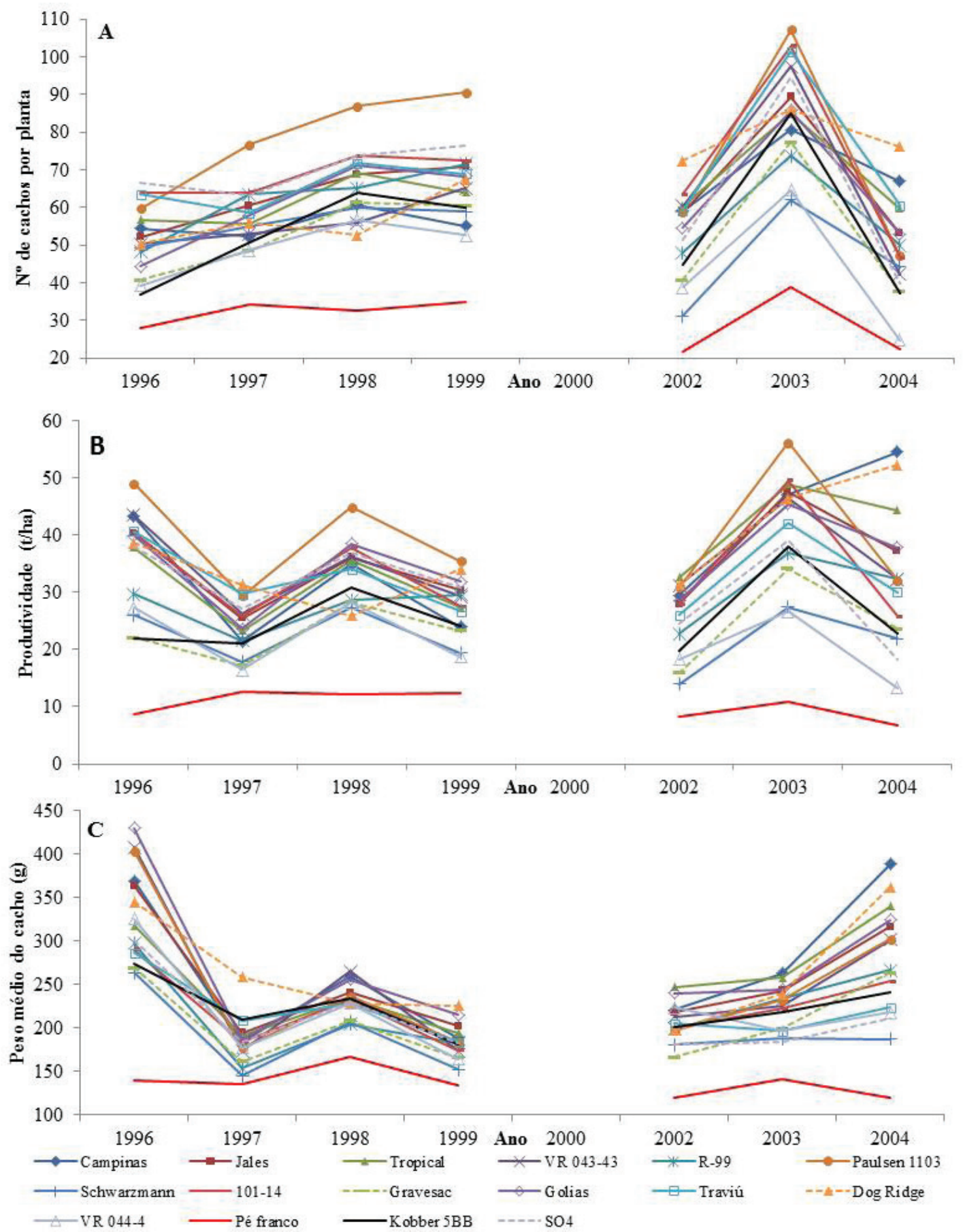

FIGURA 1- A. Número de cachos por planta. B. Produção anual de frutos $\left(\mathrm{t}^{-h a^{-1}}\right)$. C.Peso médio dos cachos (gramas) da videira 'Niágara Rosada' enxertadas em diferentes porta-enxertos e em pé-franco. 


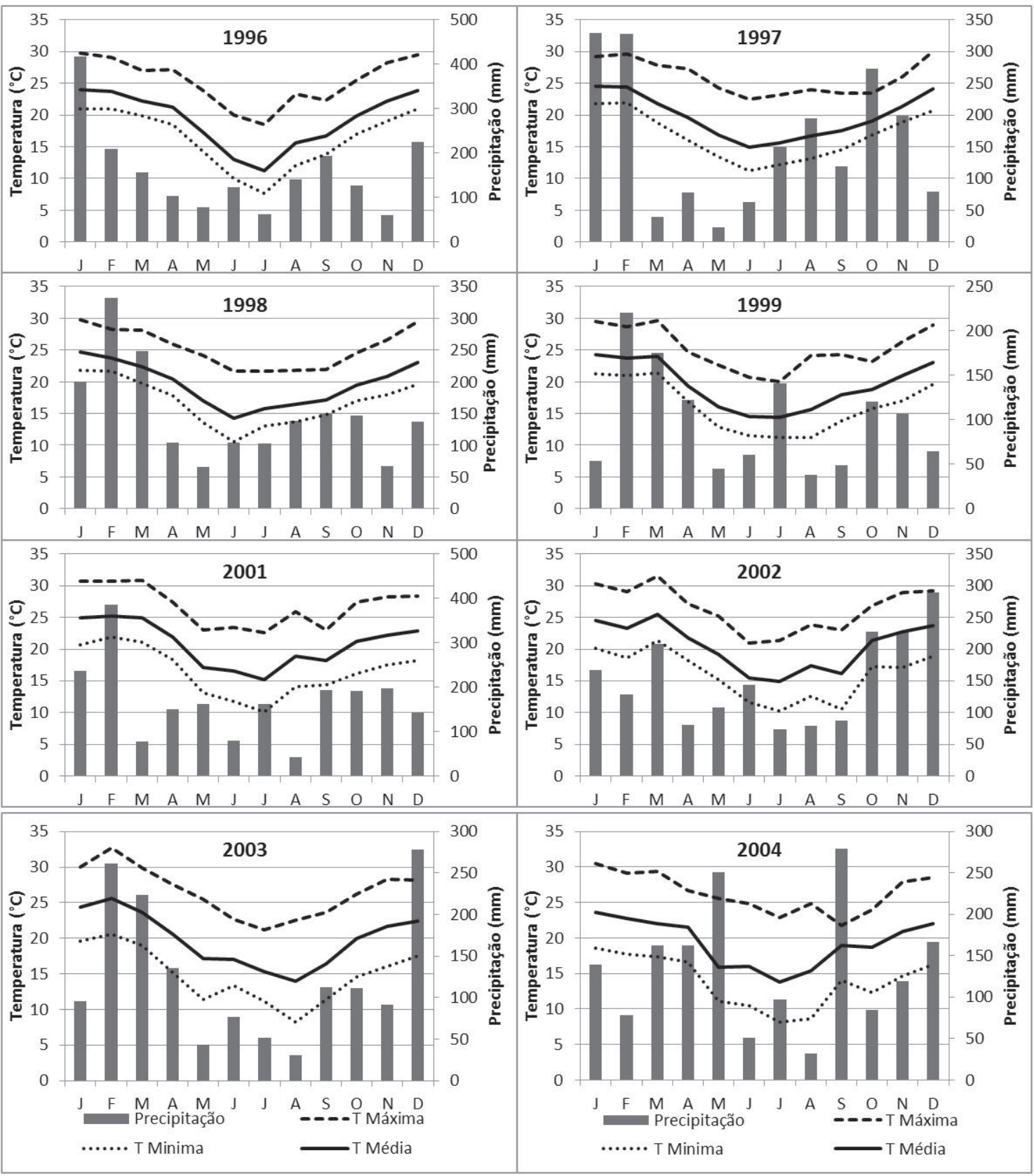

FIGURA 2- Dados de temperatura e precipitação registrados durante os anos de avaliação do experimento na Estação Meteorológica de Urussanga-SC. 


\section{CONCLUSÕES}

A videira 'Niagara Rosada' em pé-franco não é recomendada para plantio por apresentar baixa produtividade, baixo vigor, cachos pequenos e alta mortandade de plantas.

Os diferentes porta-enxertos testados não tiveram influência sobre a fenologia da cultivar- copa Niagara Rosada.

Os porta-enxertos 'Paulsen 1103', 'Campinas', 'Dog Ridge', 'Tropical', 'Golias', 'Jales', 'VR 04343' e '101-14' tiveram produtividades médias acima de 33 toneladas por hectare.

O porta-enxerto 'Dog Ridge' imprimiu vigor das plantas superior a todos os demais, seguido pelos porta-enxertos 'Paulsen 1103', 'Campinas' e 'VR 043-43'.

Os porta-enxertos 'Paulsen 1103', 'Campinas', 'Golias', 'VR 043-43', além de maior produtividade, produziram cachos com maior tamanho, sendo assim os mais indicados para produção de 'Niagara Rosada' no sul de Santa Catarina.

\section{REFERÊNCIAS}

ALVARENGA, A.A.; REGINA, M.D.A.; FRÁGUAS, J.C.; CHALFUN, N.N.J.; SILVA, A.D. Influência do porta-enxerto sobre o crescimento e produção da cultivar de videira Niágara Rosada (Vitis labrusca L. x Vitis vinifera L.), em condições de solo ácido. Ciência e Agrotecnologia, Lavras, v.26, p.1459-1464, 2002.

BACK, A.J.; BRUNA, E.D. Soma térmica nas fases fenológicas da videira 'Niagara Rosada' cultivada em Urussanga, Santa Catarina. Agropecuária Catarinense, Florianópolis, v.25, n.3, p.85-89, 2012.

BILLONES-BAAIJENS, R.; JONES, E.E.; RIDGWAY, H.J.; JASPERS, M.V. Susceptibility of common rootstock and scion varieties of grapevines to Botryosphaeriaceae species. Australasian Plant Pathology, Toowoomba East, v.43, n.1, p.25-31, 2014.
CAMARGO, U.G. Uvas viníferas para processamento em regiões de clima temperado. Bento Gonçalves: Embrapa Uva e Vinho, 2003. (Sistemas de Produção, 4). Disponível em: <http://www.cnpuv.embrapa.br/publica/sprod/ UvasViniferasRegioesClimaTemperado/cultivar. htm>. Acesso em: jun. 2014.

CAMPOY, J.A.; RUIZ, D.; EGEA, J. Dormancy in temperate fruit trees in a global warming context: a review. Scientia Horticulturae, The Hague, v. 130, p.357-372, 2011.

COOKSON, S.J.; OLLAT, N. Grafting with rootstocks induces extensive transcriptional reprogramming in the shoot apical meristem of grapevine. BMC Plant Biology, Villenave d'Ornon, v.13, n.1, p.147, 2013.

SILVA, T.P.; PIO, R.; SALI, A.B.; DALASTRA, I.M.; STANGARLIN, J.R.; KUHN, O.J. Avaliação de porta-enxertos de videira em condições subtropicais. Bragantia, Campinas, v.69, n.1, p.9397, 2010.

EDWARDS, M. Effects of the type of rootstock on yields of Catarina grapevines (Vitis vinifera) and levels of citrus nematode (Tylenchulus semipenetrans Coob.). Australian Journal of Experimental Agriculture, Collingwood, v.28, n.2, p.283-286, 1988 .

FERREIRA, E.A.; REGINA, M.R.; CHALFUN, N.N.J.; ANTUNES, L.E.C. Antecipação de safra para videira 'Niágara Rosada' na região sul do estado de Minas Gerais. Ciência e Agrotecnologia, Lavras, v.28, n.6, p.1221-1227, 2004.

FERRIS, H.; ZHENG, L.; WALKER, M. A. Resistance of grape rootstocks to plant-parasitic nematodes. Journal of Nematology, Hanover ,v.44, n.4, p.377-386, 2012.

GARRIDO, L.R.; SÔNEGO, O.R.; GOMES, V.N. Fungos associados com o declínio e morte de videiras no Estado do Rio Grande do Sul. Fitopatologia Brasileira, Brasília, v.29, n.3, p.322-324, 2004.

GONÇALVES, C.A.A.; LIMA, L.C.O.; CHALFUN, N.N.J.; ALVARENGA, Â.A; DE SOUZA, M.T. Fenologia e qualidade do mosto de videiras 'folha de figo' sobre diferentes porta-enxertos, em caldas, sul de minas gerais. Ciência e Agrotecnologia, Lavras, v.26, n.6, p.1178-1184, nov./dez., 2002. 
HIDALGO, L. Tratado de viticultura general. Madrid: Mundi-Prensa, 1993. 983 p.

JOGAIAH, S.; RAMTEKE, S.D.; SHARMA, J.; UPADHYAY, A.K. Moisture and salinity stress induced changes in biochemical constituents and water relations of different grape rootstock cultivars. International Journal of Agronomy, Maharashtra, v.2014, p.1-8, 2014.

JONES, H.G.; HILLIS, R.M.; GORDON, S.L.; BRENNAN, R.M. An approach to the determination of winter chill requirements for different Ribes cultivars. Plant Biology, Dundee, v.15, p.18-27, 2013.

LUEDELING, E.; GUO, L.; DAI, J.; LESLIE, C.; BLANKE, M. M. Differential responses of trees to temperature variation during the chilling and forcing phases. Agricultural and Forest Meteorology, Amsterdam, v.181, n. 33-42, 2013.

MUROLO, S.; ROMANAZZI, G. Effects of grapevine cultivar, rootstock and clone on esca disease. Australasian Plant Pathology, Clayton, v.43, n.2, p.215-221, 2014.

PASTENA, B. Tratado de viticultura italiana. 2. ed. Bolonha: Edagrícola, 1981. 1011 p.

PAULETTO, D.; MOURÃO FILHO, F.A.A.; KLUGE, R.A.; SCARPARE FILHO, J.A. Produção e vigor da videira 'Niágara Rosada' relacionados com o porta-enxerto. Pesquisa Agropecuária Brasileira, Brasília, v.36, n.1, p.115-121, 2001a.

PAUlETTO, D.; MOURÃO FILHO, F.A.A.; KLUGE, R.A.; SCARPARE FILHO, J.A. Efeito do porta-enxerto na qualidade do cacho da videira 'Niagara Rosada'. Pesquisa Agropecuária Brasileira, Brasília, v.36, n.7, p. 935-939, 2001 b.

POMMER, C.V.; PASSOS, I.R.S.; TERRA, M.M.; PIRES, E J.P. Variedades de videira para o Estado de São Paulo. Campinas: Instituto Agronômico, 1997. 59 p. (Boletim Técnico, 166).
SATO, A.J.; SILVA, B.J.; BERTOLUCCI, R.; CARIELO, R.M.; GUIRAUD, M.C.; FONSECA, I.C.B.; ROBERTO, S.R. Evolução da maturação e características físico-químicas de uvas da cultivar Isabel sobre diferentes porta-enxertos na Região Norte do Paraná. Semina: Ciências Agrárias, Londrina, v.30, n.1, p.11-20, 2009.

SERRA, I.A.; STREVER, A.; MYBURGH, P.A.; DELOIRE, A. Review: the interaction between rootstocks and cultivars (Vitis vinifera L.) to enhance drought tolerance in grapevine. Australian Journal of Grape and Wine Research, Adelaide, v.20, n.1, p.1-14, 2014.

SOCIEDADE BRASILEIRA DE CIÊNCIA DO SOLO. Manual de adubação e de calagem para os Estados do Rio Grande do Sul e de Santa Catarina. 10.ed. Porto Alegre, 2004. 400p.

TERRA, M.M.; PIRES, E.J.P.; POMMER, C.V.; BOTELHO, R.V. Produtividade da cultivar de uva de mesa Niágara Rosada sobre diferentes portaenxertos, em Monte Alegre do Sul-SP. Revista Brasileira de Fruticultura, Jaboticabal,v.25, n.3, p.549-551, 2003.

TERRA, M.M.; POMMER, C.V.; PIRES, E.J.P.; RIBEIRO, I.J.A.; GALLO, P.B.; PASSOS, I.R.D.S. Produtividade de cultivares de uvas para suco sobre diferentes porta-enxertos IAC em Mococa-SP. Revista Brasileira de Fruticultura, Jaboticabal, v.23, n.2, p.382-386, 2001.

TSEGAY, D.; AMSALEM, D.; ALMEIDA, M.; CRANDLES, M. Responses of grapevine rootstocks to drought stress. International Journal of Plant Physiology and Biochemistry, Montpellier, v.6, n.1, p.1-6, 2014.

VILLA NOVA, N. A.; PEDRO JUNIOR, M. J.; PEREIRA, A. R.; OMETTO, J. C. Estimativa de graus dia acumulados acima de qualquer temperaturabase em função das temperaturas máxima e mínima. Ciência da Terra, São Paulo, n.30, p.1-8, 1972. 